\title{
ERCC6L promotes the progression of hepatocellular carcinoma through activating PI3K/AKT and NF-KB signaling pathway
}

Han Chen, Hengxiao Wang, Xiqiao Yu, Shuping Zhou, Yueying Zhang, Zhaopeng Wang, Shuhong Huang and Zhaoxia Wang ${ }^{*}$ (D)

\begin{abstract}
Background: Excision Repair Cross-Complementation group 6-like (ERCC6L) has been shown to exhibit carcinogenic effect in several malignant tumors. However, the function and molecular mechanism of the ERCC6L in hepatocellular carcinoma (HCC) have not been investigated extensively.

Methods: Immunohistochemistry analyses were used to detect ERCC6L expression in a HCC tissue microarray, and the Chi-square test was used to assess the correlation between ERCC6L expression and patients' clinicopathological features. shRNA was used to down-regulation ERCC6L expression in HCC cell lines. MTT assay, plate clone formation assay, flow cytometry, caspase 3/7 activity and migration assays were performed to evaluate the impact of ERCC6L on $\mathrm{HCC}$ cells in vitro. Nude mice xenograft models were used to assess the role of ERCC6L in vivo. The regulatory of mechanism of PI3KJAKT pathway was evaluated by western blotting.

Results: ERCC6L was highly expressed in HCC tissue compared with tumor adjacent tissues in 90 paired samples. ERCC6L expression positively correlated with gender, tumor encapsulation, and pathological stage. Patients with low ERCC6L expression had significantly longer OS than those with high ERCC6L expression. Knockdown of ERCC6L expression significantly inhibited proliferation, invasion and metastasis in vitro and tumor growth in vivo, and it promoted cell cycle arrest and apoptosis. Mechanistic analyses revealed that PI3K/AKT and NF-KB signaling pathway were inhibited by silencing ERCC6L.

Conclusion: These results demonstrate that ERCC6L plays a critical role in HCC progression, and thereby might be a potential therapeutic target for HCC patients.
\end{abstract}

Keywords: ERCC6L, Hepatocellular carcinoma, PI3K, AKT, Oncogene

\section{Background}

Hepatocellular carcinoma (HCC) is one of the most prevalent malignant tumors and the third most common cause of cancer-related deaths worldwide, often accompanied with invasive fast growing and metastasis $[1,2]$.

*Correspondence: wzxia66@126.com

Institute of Basic Medicine, Shandong First Medical University \& Shandong Academy of Medical Sciences, Jinan 250062, China
Although therapeutic strategies including surgery resection, liver transplantation and radiotherapy have greatly improved [3], there are limited effective therapies for patients with advanced HCC. The five-year post-surgical OS rate remains approximately $16 \%$ even after curative resection [4]. The main causes of poor clinical outcomes in patients with HCC are high recurrence and metastasis rates [5]. Therefore, the discovery of novel therapeutic

C C The Author(s). 2020 Open Access This article is licensed under a Creative Commons Attribution 4.0 International License, which permits use, sharing, adaptation, distribution and reproduction in any medium or format, as long as you give appropriate credit to the original author(s) and the source, provide a link to the Creative Commons licence, and indicate if changes were made. The images or other third party material in this article are included in the article's Creative Commons licence, unless indicated otherwise in a credit line to the material. If material is not included in the article's Creative Commons licence and your intended use is not permitted by statutory regulation or exceeds the permitted use, you will need to obtain permission directly from the copyright holder. To view a copy of this licence, visit http://creativecommons.org/licenses/by/4.0/ The Creative Commons Public Domain Dedication waiver (http://creativecommons.org/publicdomain/zero/1.0/) applies to the data made available in this article, unless otherwise stated in a credit line to the data. 
target and better understanding of the molecular mechanisms underlying HCC progression are crucial and urgent.

Excision repair cross-complementation group 6-like (ERCC6L), also named as Polo-like kinase 1-interacting checkpoint "helicase" (PICH), which was identified as an embryonic development related proteins, has been shown to play critical roles in regulating the development of embryonic, brain and other tissues [6-8]. Recently several reports revealed that abnormal ERCC6L expression has been detected in several malignant solid tumors consisting of breast cancer [9], kidney cancer [10], and neuroblastoma [11]. In addition, high ERCC6L expression level is related to poor prognosis in breast cancer patients, and may regulate cell proliferation, invasion and metastasis by regulating different single pathways. However, the roles of ERCC6L in HCC progression and its underlying molecular mechanisms remain unclear.

In this study, we explored the effects of ERCC6L on the progression of HCC and confirmed ERCC6L to be a poor prognostic marker. In addition, we assessed the function of ERCC6L in tumor cell proliferation, apoptosis, migration, and molecular mechanisms in vitro and in vivo. These data proposed a potential target for prognosis and therapy in HCC patients.

\section{Methods}

\section{Cell culture and transfection}

Three human HCC cell line (SMMC7721, HuH-7, Hep3B) and a normal human liver cell line HL-7702 were obtained from the Institutes of Cell Biology at the Chinese Academy of Science (Shanghai, China). The cells were recently authenticated by STR profiling and are free from mycoplasma contamination. Cells were maintained in DMEM (Gibco, Grand Island, NY, USA) supplemented with $10 \%$ fetal bovine serum, $100 \mathrm{U} / \mathrm{mL}$ penicillin, and $100 \mathrm{mg} / \mathrm{mL}$ streptomycin (Gibco, Grand Island, NY, USA) in a humidified atmosphere with 5\% $\mathrm{CO}_{2}$ at $37^{\circ} \mathrm{C}$. Transfection of shRNA (RiboBio Co., Ltd., Guangzhou, China) was performed with the transfection reagent in $2 \mathrm{nM}$ shRNA according to the manuscripts of Lipofectamin 3000 (Invitrogen, Carlsbad, USA). Target sequences as following:

ERCC6L shRNA: 5' -GGACCATATTGATCAAGTA-3';

Negative control shRNA (NC): 5'-TTCTCCGAAC GTGTCACGT-3'.

The ERCC6L cDNA was cloned into a GV219 vector (GenePharma Co. Ltd., Shanghai, China) to overexpress ERCC6L. Cells were transfected for 48 and $72 \mathrm{~h}$, then ERCC6L mRNA and protein expression were verified by quantitative real-time PCR or western blotting analysis respectively [12]..

\section{Total RNA extraction and quantitative real-time PCR}

Total RNA was isolated from cells using TRIzol reagent (Invitrogen) [13]. $1 \mu \mathrm{g}$ RNA was reversely transcribed into cDNA using Superscript First-strand Synthesis system (Invitrogen, Carlsbad, USA) according to the manufacturer's instrucions. Quantitative RT-PCR was performed using SYBR Premix Ex Tag II (Takara Bio Inc.) on a Roche 4800 instrument (Applied Biosystems, USA). The primers were following:

ERCC6L, forward: 5'-AAGGATGAACGGACCAGA AAC-3',

reverse: 5'-CTGTGAGGAGGAGGCGATTAC-3'; $\beta$-actin, forward: $5^{\prime}$-AGAGCTACGAGCTGCCTGAC-3', reverse: 5' - AGCACTGTGTTGGCGTACA-3'.

The experiment was repeated three times, and all data were analyzed by the $2^{-\Delta \Delta \mathrm{CT}}$ method.

\section{Western blotting}

Cell lysates were separated by 10\% SDS-PAGE and transferred onto polyvinylidene difluoride (PVDF) membranes (Millipore). The membranes were blocked in 5\% BSA for $1 \mathrm{~h}$, then incubated with primary antibodies overnight at $4{ }^{\circ} \mathrm{C}$. Antibodies were used as following: ERCC6L (Proteintech, 15,688-1-AP, 1:1000), PI3K (Bioss, bs-0128R, 1: 1000), p-PI3K (Ser1070; Bioss, bs-6417R, 1:1000),AKT1 (Bioss, bs-0115R, 1:1000), p-AKT1 (Thr34; Bioss, bs5194R, 1:1000), JAK2 (Bioss, bs-23003R, 1:1000), p-JAK2 (Tyr1007 + Tyr1008; Bioss, 2485R, 1:1000), NF-kB (Bioss, bs-0465R, 1:1000), p-NK-kB (Thr505; Bioss, bs-5663R, 1: 1000 ), and $\beta$-actin (Bioss, bs-0061R, 1:5000). The next day membranes were incubated with HRP-conjugated secondary antibodies for $1 \mathrm{~h}$ at $37^{\circ} \mathrm{C}$. After washed for 3 times in TBST for $5 \mathrm{~min}$, membranes were visualized by chemiluminescence kit and scanned with QuantityOne software (Bio-Rad, Hercules, CA, USA). The bands were analyzed with Image (NIH, Bethesda, MA, USA).

\section{Migration assays}

Migration assays were performed using a Transwell assay $\left(8.0 \mu \mathrm{m}, 24\right.$ well, BD Biosciences). Briefly, $1 \times 10^{5}$ cells were added into the upper chambers with serumfree DMEM, and the lower chambers were filled with $600 \mu \mathrm{L}$ DMEM contained 10\% FBS. After incubated for $24 \mathrm{~h}$, the cells that migrated were fixed for $30 \mathrm{~min}$ and stained with $0.05 \%$ crystal violet. The numbers of migrating cells were counted in five randomly selected visual fields under a microscope at 200× magnification [14]. The experiments were performed three times.

\section{MTT assays}

Cells were inoculated into a 96-well plate at $2 \times 10^{3}$ cells/well and cultured for 24,48 , and $72 \mathrm{~h}$ respectively. Then, $20 \mu \mathrm{L}$ of $5 \mathrm{mg} / \mathrm{mL}$ MTT solution (Sigma, USA) was added and incubated for $4 \mathrm{~h} .150 \mu \mathrm{L}$ of dimethyl 
sulfoxide (DMSO) was added and the optical density (OD) value was measured at $490 \mathrm{~nm}$ of the microplate reader. he experiments were performed three times separately.

\section{Cell colony formation}

Cells were seeded into 6-well plates at a density of 500 cells/well for 14 days. Then cells were fixed with $4 \%$ paraformaldehyde for $30 \mathrm{~min}$, and stained with $0.05 \%$ crystal violet for $20 \mathrm{~min}$. Representative photographs were captured, and colonies with more than 40 cells were counted.

\section{Cell cycle analysis}

For cell cycle analysis, cells transfected with shERCC6L or NC for $24 \mathrm{~h}$. Cells were fixed in $70 \%$ ethanol, and stained with $50 \mu \mathrm{g} / \mathrm{mL}$ PI for $30 \mathrm{~min}$ in the dark at $37^{\circ} \mathrm{C}$. The percentage of cells in the G1, S, and G2 phases were determined with a FACS flow cytometer (Becton Dickinson, San Jose, USA).

\section{Apoptosis assay}

Apoptosis was evaluated by flow cytometry using an Annexin V/FITC-PI Apoptosis Detection Kit (Millipore, USA) according to the manufacturer's instructions. After washing with cold PBS, tumor cells were stained with $10 \mu \mathrm{L}$ of Annexin V-FITC/PI in the dark for $15 \mathrm{~min}$ at room temperature and $400 \mu \mathrm{L}$ of binding buffer was added. The cells were analyzed by flow cytometry (BD Biosciences, MA, USA). The Q2 and Q3 quadrants were determined as the early and late apoptosis induced cell, respectively. The percentage of total apoptosis (early and late stages) was used for quantitative analysis.

\section{Caspase-3/7 activity}

Cell were transfected for with shERCC6L or NC $24 \mathrm{~h}$, then collected and incubated with the working solution provided in the Caspase-Glo 3/7 Assay Kit (Promega) according to manufacturer's protocol [15].

\section{Immunohistochemistry (IHC)}

The tissue microarray (HLivH180Su18, Outdo Biotech) was used to validate ERCC6L expression in 90 HCC tissue samples and tumor-adjacent tissues. Briefly, the samples were dewaxed, and antigens were retrieved using a microwave. The paraffin section were dewaxed with $x y-$ lene ( $10 \mathrm{~min} \times 3$ times), followed by rehydration with gradient ethanol (anhydrous ethanol, 95\% ethanol, 90\% ethanol, $80 \%$ ethanol, $70 \%$ ethanol, 5 min each), and then antigens were retrieved using microwave for $15 \mathrm{~min}$. After elimination of endogenous peroxidase activity, sections were blocked with $5 \%$ bovine serum albumin and then incubated with primary antibodies against ERCC6L (Bioss, bs-6380R, 1:100) overnight at $4{ }^{\circ} \mathrm{C}$. Then sections were incubated with secondary antibodies (horseradish peroxidase (HRP)-conjugated goat anti-rabbit IgG (A0208, Beyotime, China) for $1 \mathrm{~h}$. Sections were stained with Diaminobenzidine (DAB) solution and observed under a microscope (Leica DM4000B, Germany) as previously described [16].

Two pathologists who were separately blinded to the clinicopathological data evaluated the stained results independently. Staining intensity was scored as follows $[17,18]$ : 0 , negative; 1 , weak; 2 , moderate; and 3 , strong. The percentage of positive-stained cells was divided according to density: $0-10 \% ; 11-25 \% ; 26-50 \% ; 51-75 \%$; $\geq$ $76 \%$, and score was $0,1,2,3,4$ respectively. The total scores was calculated by multiplying the intensity scores by the percentage scores; total scores of $0-3$ or $4-12$ were defined as low or high expression.

\section{Xenografts tumor growth}

BALB/c nude mice were obtained from Beijing Vital River Laboratory Animal Technology Co., Ltd. (male, 6 weeks old, 18-20 g). Animal experiments were approved by the Institute of Basic Medicine, Shandong First Medical University \& Shandong Academy of Medical Sciences and were performed according to the established guidelines. Mice were fed under the condition of specific pathogen-free. shERCC6L and NC were used to construct lentiviral particles (GenePharma), and the lentivirus were infection to establish stable transfected cells. Mice were randomly grouped two groups (with 7 mice each group): negative control group (NC group, injected with SMMC7721 transfected with NC) and shERCC6L group (injected with SMMC7721 transfected with shERCC6L). A total of $1 \times 10^{7}$ cells were suspended in $100 \mu \mathrm{L}$ serum-free DMEM and injected subcutaneously into the right back of mice. After injection, the long diameter (L), width diameter (W) of tumors were measured every 5 days, and the volumes of tumor were calculated as following Volume $(\mathrm{V})=\left(\mathrm{W}^{2} \times \mathrm{L}\right) / 2$. Mice were anaesthetized by intraperioneal injection of pentobarbital sodium overdose $(100 \mathrm{mg} / \mathrm{kg})$ on the 30th day. Euthanasia was considered to be successful if there was cardiac arrest and no spontaneous breath for $3 \mathrm{~min}$, and then tumors were taken out and weighed.

\section{Statistical analysis}

All statistical analyses were performed using SPSS 22.0 Software (NY, USA). All measured data were presented as the mean $\pm S D$, and Student's $t$-tests were used for comparing the significance of differences between two groups. OS were calculated using the Kaplan-Meier method, and survival curve comparisons were performed using the log-rank test. Univariate and multivariate Cox regression was used for analysis factors predicting OS. $p<0.05$ was considered the statistical significance. 


\section{Results}

\section{ERCC6L expression is upregulated in HCC patients}

To investigate the clinical significance of ERCC6L expression in patients with $\mathrm{HCC}$, we examined its expression in a human HCC tissue array consisting of 90 paired HCC and tumor-adjacent tissues by IHC. As shown in Fig. 1a, ERCC6L was localized in the cytoplasm of HCC cells, and its expression was evidently higher in tumor tissue than in adjacent tissues $(p<0.05$, Fig. $1 b-c)$. We then divided the patients into high or low ERCC6L expression groups according to the IHC staining score and evaluated overall survival (OS) by KaplanMeier analysis. Compared with the low ERCC6L expression group, patients with high ERCC6L expression exhibited markedly shorter overall survival time $(p<0.05$; Fig. 1d).

To investigate whether ERCC6L protein expression was associated with $\mathrm{HCC}$ progression, we analyzed the relationship between ERCC6L expression and clinical characteristics. ERCC6L expression positively correlated with gender, tumor encapsulation, and pathological stage ( $p=0.012,0.004$, and 0.027 , respectively), but not with age, liver cirrhosis, tumor size, tumor number (Table 1.). Univariate analysis showed that ERCC6L, tumor size and pathological stage were correlated with OS in HCC patients. In addition, a multivariate analysis demonstrated that the ERCC6L (HR 0.437, $p=0.045$ ), the tumor size (HR 0.449, $p=0.037$ ) and gender (HR 2.970, $p=0.026$ ) were independent prognostic indicators for HCC patients (Table 2.).Taken together, these data suggest that ERCC6L expression levels are positively correlated with poor OS in HCC patients, indicating that ERCC6L are prognostic indicators for $\mathrm{HCC}$.

\section{ERCC6L down-regulation suppresses tumor cell proliferation and migration in vitro}

To explore the biological function of ERCC6L in HCC, we performed RT-qPCR to determine ERCC6L mRNA expression levels in three HCC cells lines and a normal liver cell line. As shown in Fig. 1e, ERCC6L mRNA level was significantly elevated in HCC cell lines than that of HL-7702 cell lines, particularly SMMC-7721 and HuH-7 cells $(p<0.05)$. Thus, SMMC-7721 and $\mathrm{HuH}-7$ cells were used in subsequent experiments. A shR-ERCC6Lmediated loss-of-function approach was used to knockdown ERCC6L expression in SMMC7721 and HuH-7 cells. qRT-PCR and Western blotting results confirmed that the expression of ERCC6L mRNA and proteins

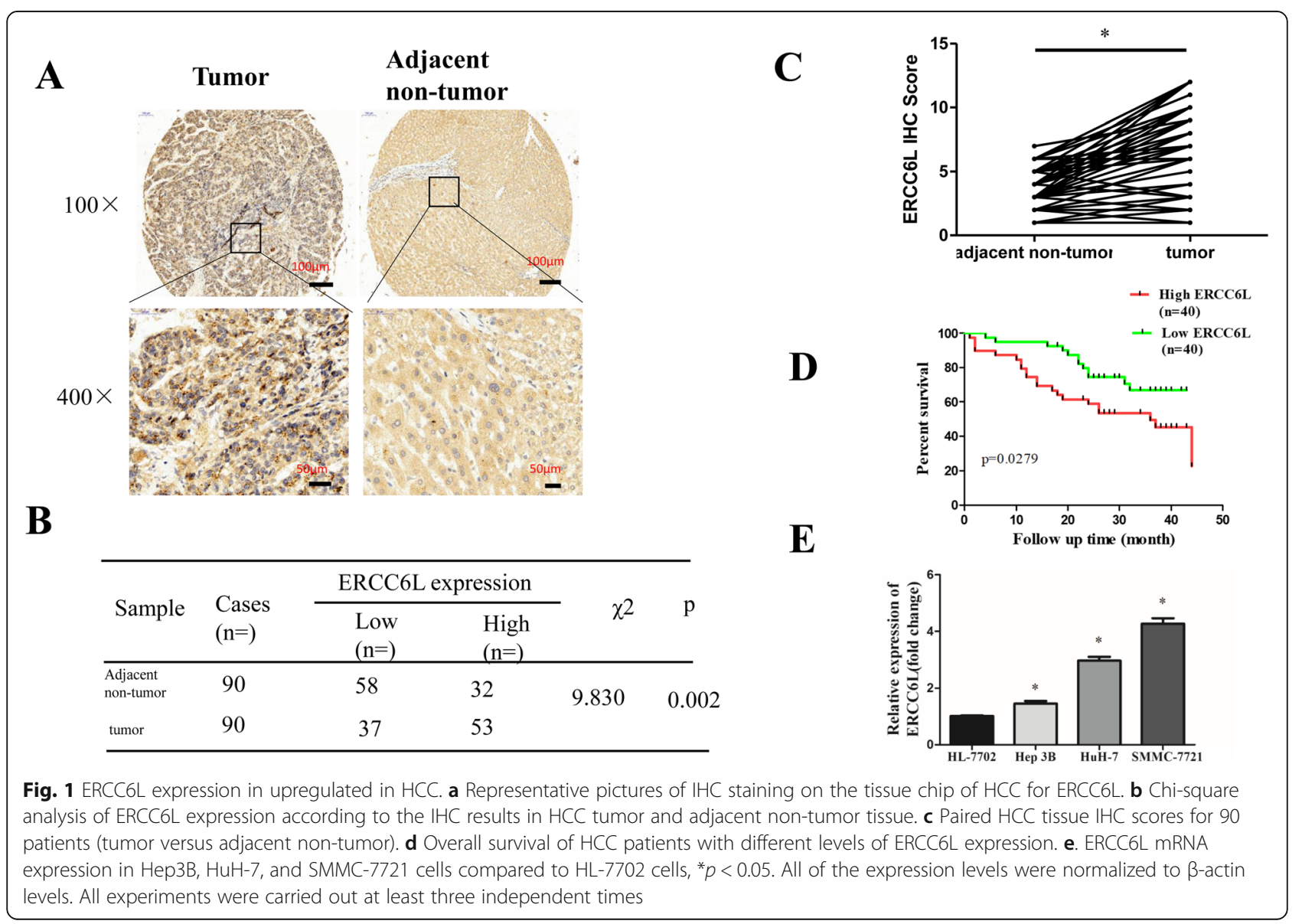


Table 1 Correlation between ERCC6L protein expression in HCC and the clinical characteristics of HCC patients $(n=90)$

\begin{tabular}{|c|c|c|c|c|c|}
\hline \multirow{2}{*}{$\begin{array}{l}\text { Clinical } \\
\text { characteristics }\end{array}$} & \multirow[t]{2}{*}{$\mathbf{n}$} & \multicolumn{2}{|c|}{ ERCC6L expression } & \multirow[t]{2}{*}{$x^{2}$} & \multirow[t]{2}{*}{$P$} \\
\hline & & Low & High & & \\
\hline \multicolumn{6}{|l|}{ Age, years } \\
\hline$<50$ & 27 & 9 & 16 & 0.207 & 0.810 \\
\hline$\geq 50$ & 63 & 26 & 37 & & \\
\hline \multicolumn{6}{|l|}{ Gender } \\
\hline Female & 16 & 2 & 14 & 6.580 & 0.012 \\
\hline Male & 74 & 35 & 39 & & \\
\hline \multicolumn{6}{|l|}{ Liver cirrhosis } \\
\hline No & 73 & 32 & 41 & 0.475 & 0.584 \\
\hline Yes & 17 & 5 & 12 & & \\
\hline \multicolumn{6}{|l|}{ Tumor size, cm } \\
\hline$<5$ & 31 & 15 & 16 & 1.034 & 0.370 \\
\hline$\geq 5$ & 59 & 22 & 37 & & \\
\hline \multicolumn{6}{|l|}{ Tumor number } \\
\hline Single & 83 & 32 & 51 & 2.882 & 0.119 \\
\hline Multiple & 7 & 5 & 2 & & \\
\hline \multicolumn{6}{|c|}{ Tumor encapsulation } \\
\hline Complete & 65 & 33 & 32 & 9.016 & 0.004 \\
\hline None & 25 & 4 & 21 & & \\
\hline \multicolumn{6}{|c|}{ Pathological stage } \\
\hline$|-| \mid$ & 64 & 31 & 33 & 4.912 & 0.027 \\
\hline III-IV & 26 & 6 & 20 & & \\
\hline
\end{tabular}

were significantly decreased in SMMC7721 and HuH-7 cells transfected with shERCC6L than NC group $(p<$ 0.05; Fig. 2 a-b).

MTT assays were used to measure cell proliferation. As shown in Fig. 2c, the proliferation of SMMC-7721 and $\mathrm{HuH} 7$ cells transfected with shERCC6L was significantly lower than that of NC cells $(p<0.05)$. Consistent with results of MTT assay, the capacity of colony formation with ERCC6L-knockdown HCC cells was significantly decreased than that of NC cells (Fig. 2d, $p<0.05$ ).
The effects of silencing ERCC6L on HCC cell invasion were tested using a Transwell assay. As shown in Fig. 2e, the number of migratory shR-ERCC6L-transfected SMMC-7721 cells $(64.67 \pm 5.73)$ was significantly lower than the number of $\mathrm{NC}$ cells $(157.67 \pm 8.99, p<0.05)$. Similar results were obtained for HuH-7 cells, with significantly fewer cells migrating through the Transwell membrane in the shERCC6L group $(57.67 \pm 9.10)$ than in the NC group $(172.33 \pm 6.13 ; p<0.05)$. Collectively, these data indicated that downregulation of ERCC6L suppressed HCC cell proliferation and migration in vitro.

\section{Downregulation of ERCC6L induces cell cycle arrest and apoptosis in HCC cells}

To determine the regulation of ERCC6L in cell cycle and apoptosis, we analyzed the cell cycle by flow cytometry. As shown in Fig. 3a, the percentage of cells in G1 phase was significantly higher in the shERCC6Ltransfected SMMC7721 cells $(81.73 \pm 2.56 \%)$ than in the NC group (50.71 $\pm 3.21 \% ; p<0.05)$. Similarly, the percentage of cells in G0/G1 phase was significantly higher in shERCC6L-transfected $\mathrm{HuH}-7$ cells $(81.76 \pm 3.72 \%)$ than in the NC group $(62.24 \pm 4.33 \%, p<0.05)$. Thus it could be concluded that knockdown ERCC6L induces G1 phase cell cycle arrest.

Next, Annexin V-FITC and propidium iodide (PI) double staining was used to detect the apoptosis rate of SMMC7721 and HuH-7 cell by flow cytometry. As shown in Fig. 3b, the ratio of apoptotic SMMC7721 cells was dramatically higher in the shERCC6L-treated group $(31.77 \pm 1.090 \%)$ than in the NC group $(5.597 \pm 0.403 \%$, $p<0.001)$ and the rate of $\mathrm{HuH}-7$ cell apoptosis was also higher in the shERCC6L-treated group $(26.53 \pm 1.244 \%)$ than in the NC group $(6.377 \pm 0.680 \%, p<0.001)$.

The apoptosis induction mechanism was analyzed by detecting caspases-3/7 activation with Caspase-Glo ${ }^{\circ}$ 3/7 Assay Kit. The same tendency was observed as above, knockdown ERCC6L caused a significantly enhancing in caspase-3/7 activity than NC group (SMMC7721:

Table 2 Univariate and multivariate Cox regression analyses of overall survival

\begin{tabular}{|c|c|c|c|c|}
\hline \multirow[t]{2}{*}{ Clinical characteristics } & \multicolumn{2}{|c|}{ Univariable analysis } & \multicolumn{2}{|c|}{ Multivariabl analysis } \\
\hline & HR (95\%) & $P$ value & HR (95\%) & $P$ value \\
\hline Age, years (< 50 vs. $\geq 50$ ) & $0.820(0.441-1.526)$ & 0.532 & $1.143(0.592-2.207)$ & 0.691 \\
\hline Gender (Female vs. male) & $2.253(0.885-5.737)$ & 0.089 & $2.970(1.141-7.730)$ & 0.026 \\
\hline Liver cirrhosis (No vs. Yes) & $0.577(0.244-1.368)$ & 0.212 & $0.787(0.311-1.991)$ & 0.613 \\
\hline Tumor size, $\mathrm{cm}(<5$ vs. $\geq 5$ ) & $0.365(0.176-0.758)$ & 0.007 & $0.449(0.211-0.953)$ & 0.037 \\
\hline Tumor number (Single vs. Multiple) & $1.436(0.512-4.025)$ & 0.492 & $2.242(0.725-6.930)$ & 0.161 \\
\hline Tumor encapsulation (Complete vs. None) & $1.245(0.662-2.341)$ & 0.496 & $0.945(0.481-1.860)$ & 0.871 \\
\hline Pathological stage (I-II vs. III-IV) & $2.134(1.173-3.881)$ & 0.013 & $1.729(0.860-3.478)$ & 0.124 \\
\hline ERCC6L (high vs. low) & $0.463(0.234-0.917)$ & 0.027 & $0.437(0.195-0.982)$ & 0.045 \\
\hline
\end{tabular}




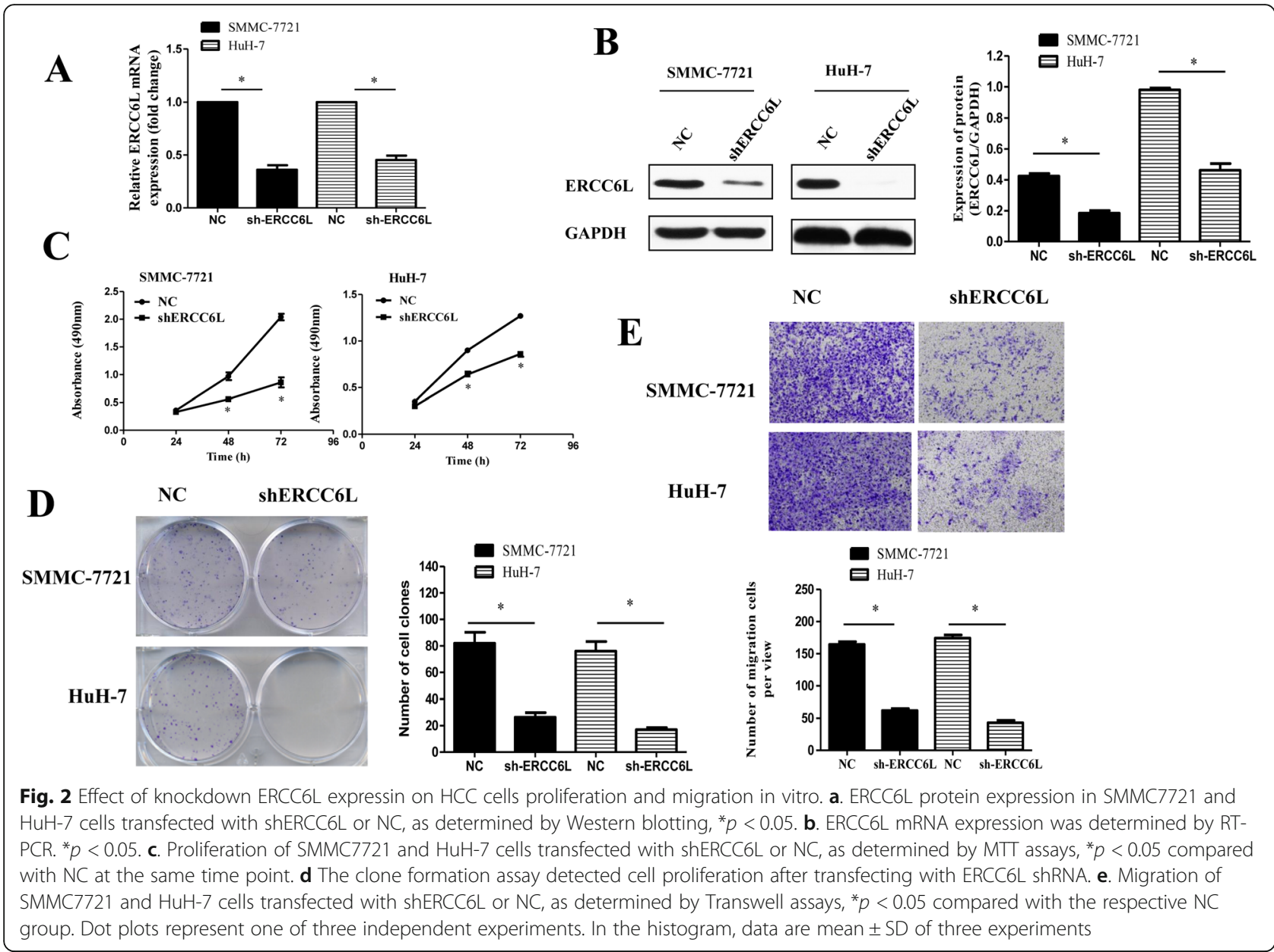

$344.91 \pm 0.64$ vs. $100.0 \pm 0.75, p<0.001 ;$ Huh-7: $311.65 \pm$ 1.58 vs. $100.0 \pm 3.47, p<0.001$ ) (Fig. 3c). These findings further demonstrated that knockdown of ERCC6L can effectively induce HCC cell apoptosis in a caspase-3/7dependent manner and ERCC6L be involved in the regulation of the cell cycle and apoptosis.

\section{ERCC6L modulates HCC growth through PI3K/AKT and NF-KB signaling pathway}

Previous studies showed that Phosphatidelinositol 3 kinase/Protein Kinase B (PI3K/AKT) signaling pathway is responsible for cancer proliferation, metastasis, angiogenesis, and survival [19-21]. NF-kB is a pleiotropic transcription regulating inflammation, cell survival and proliferation, which represents an important link between inflammation and tumorigenesis [22]. To explore whether PI3K/AKT and NF- $\mathrm{kB}$ involved in ERCC6Linduced $\mathrm{HCC}$, we knockdown or overexpress ERCC6L expression in SMMC7721 and $\mathrm{HuH}-7$ cells, respectively. Western blot analysis was performed to determine the expression of PI3K/AKT signaling-related molecules. As shown in Fig. 4a-b, compared with NC, shERCC6L decreased the levels of phosphorylated PI3K (p-PI3K), phosphorylated AKT (p-AKT) and phosphorylated NF$\kappa \mathrm{B}(\mathrm{p}-\mathrm{NF}-\mathrm{kB})\left({ }^{*} p<0.05\right)$, whilst the levels of nonphosphorylated PI3K, AKT and NF- $\mathrm{BB}$ remained unchanged. Furthermore, deguelin, a specific inhibitor of AKT was applied. ERCC6L- induced activation of PI3K/ AKT signaling pathway were reversed by deguelin $(5 \mu \mathrm{M} / \mathrm{L}, 4 \mathrm{~h}) \quad(\# p<0.05)$. Deguelin $(5 \mu \mathrm{M} / \mathrm{L}, 4 \mathrm{~h})$ also blocked ERCC6L induced activation of NF-kB (Fig. 4a-b, Fig. S1). Altogether, regulation of ERCC6L confirmed that PI3K/AKT and NF- $\mathrm{KB}$ pathway were involved in the ERCC6L-mediated oncogenic function.

\section{ERCC6L down-regulation inhibits tumor growth in vivo} To further determine the role of ERCC6L in tumor growth, we established xenograft tumor mouse model. Compared with that in NC group, tumor growth in the shERCC6L was significantly inhibited $(p<0.05$, Fig. 5ab). Moreover, the tumor weight in the shERCC6L group was significantly decreased than that in NC group $(p<$ 0.05, Fig. 5c), showing that knockdown ERCC6L expression could retard HCC growth in vivo. 


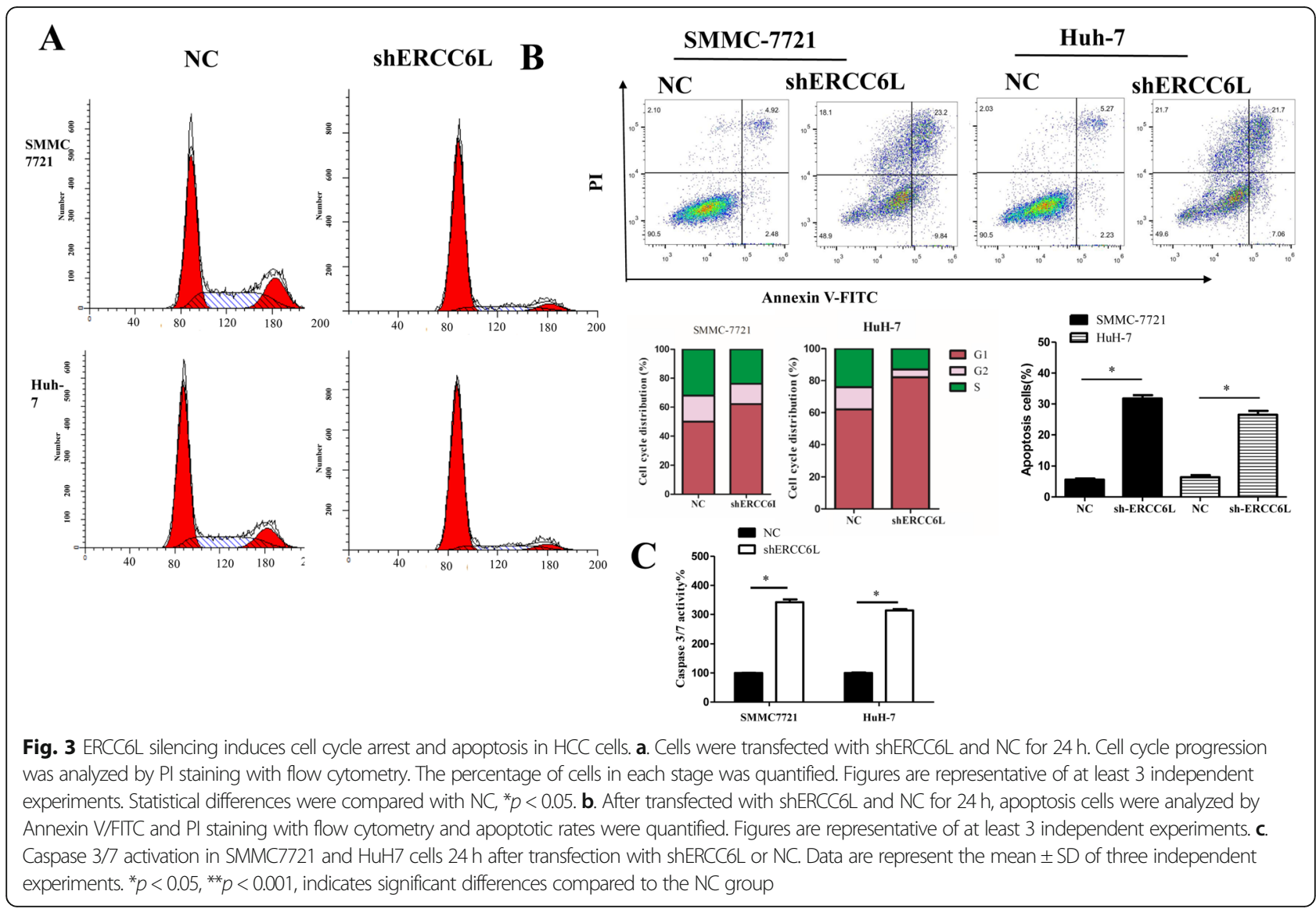

\section{Discussion}

$\mathrm{HCC}$ is an aggressive malignancy, which metastasis, invasion, and recurrence are the main causes of death in HCC patients [23]. Rapid HCC progression and difficulty detecting early disease are major obstacles to curative treatment [24]. It is urgently required to screen novel diagnostic or prognostic biomarkers for targeted therapy. In this study, we found that higher ERCC6L expression levels are detected in tumor tissues than in adjacent normal tissues, suggesting that ERCC6L may play a crucial role in the progression of HCC. Moreover, high ERCC6L expression is a prognostic factor for reduced OS in HCC patients. Knockdown ERCC6L could inhibit HCC cell proliferation, invasion in vitro and vivo. In the aspect of molecular mechanism, we confirmed that PI3K/AKT and NF- $\mathrm{kB}$ pathway were involved in the regulation of ERCC6L. Taken together, our findings reveal that ERCC6L overexpression correlates with the development of the malignant tumor and may be an effectively prognostic factor and potential therapeutic target for HCC patients.

Increasing evidences have demonstrated that ERCC6L is an important oncogene in tumor progression. $\mathrm{Pu}$ et al. [10] observed that knockdown ERCC6L expression inhibited the proliferation of breast and kidney cancer cell in vitro and vivo. Upregulated ERCC6L mRNA was notably correlated with the progress of tumor and associated with poorer outcomes in breast and kidney cancer patients. They also found that RAB31 may be as ERCC6L downstream protein involved in the progression of cancer via phosphorylated MAPK and CDK. Zhang et al. [25] analyzed a tissue microarray containing 150 renal cell carcinoma (RCC) samples showed that compared with adjacent tissue, ERCC6L was overexpressed in the tumor tissues, and abnormal expression was positively correlated with the cancers progression. Meanwhile, knockdown ERCC6L expression inhibited RCC cells viability and induced apoptosis accordingly. In terms of mechanism, they confirmed that MAPK signaling pathway was involved in the regulation of ERCC6L on cellular process of RCC. Zhong et al. [11] showed that four genes (ERCC6L, AHCY, STK33, and NCAN) have been identified to increase in the neuroblastoma and predicted poor prognosis of neuroblastoma patients. Of these, ERCC6L was an independent prognostic factor of overall survival and event-free survival. Furthermore, they identified that some special genes such as MAD2L, CCNB1 and BIRC5, which had a close relationship with ERCC6L were involved in the cell cycle pathway, thus ERCC6L may play an important role in neuroblastoma. 

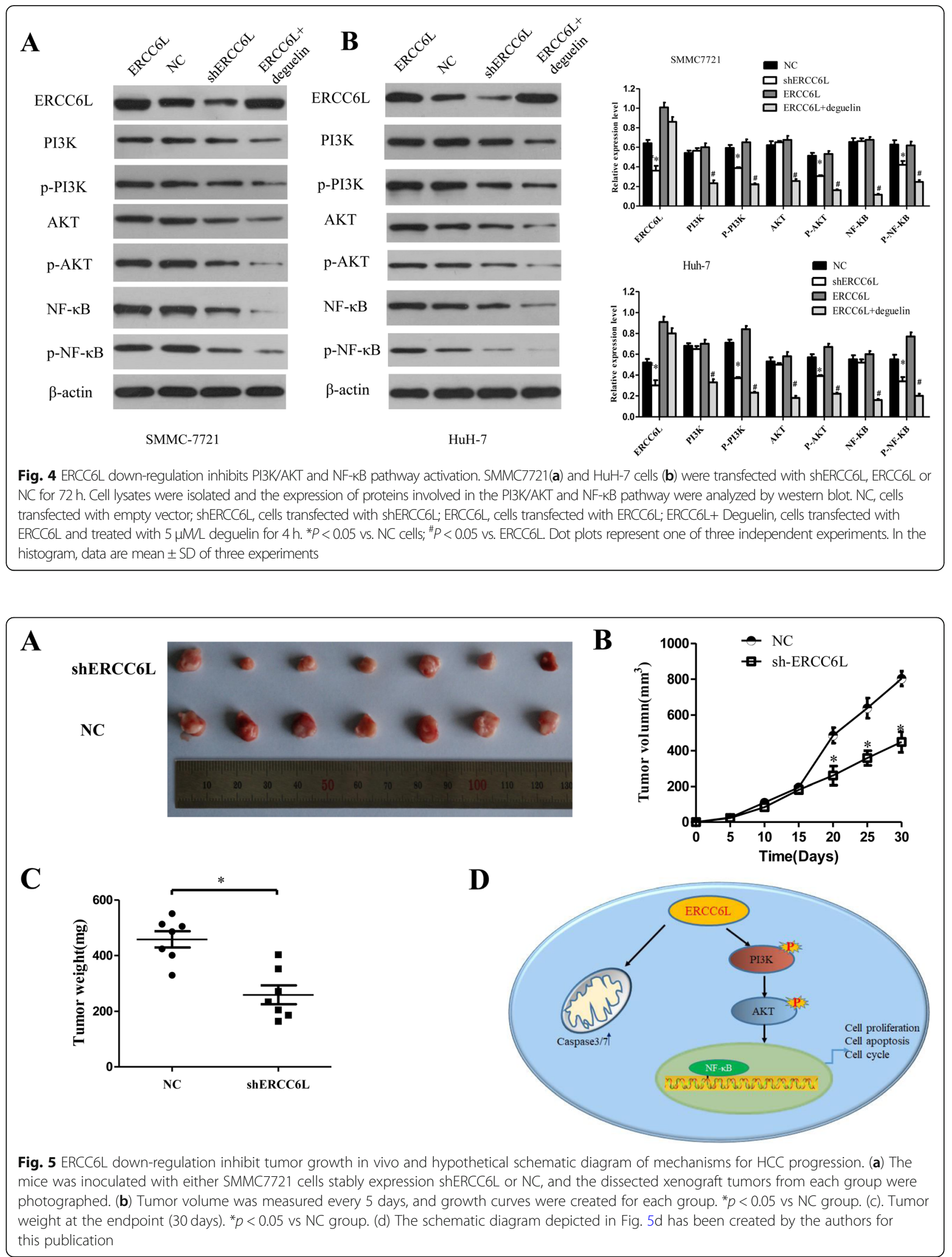
Recently, Xie et al. [26] found that ERCC6L was abnormal overexpressed in colorectal cancer (CRC) tissues and cell lines, and reducing ERCC6L expression in CRC cells significantly inhibited the proliferation, cell cycle progression, and arrested cell cycle at G0/G1 phase. These findings demonstrated that ERCC6L may exert an essential role in tumor growth and may be an efficient target for tumor detection, diagnosis and therapy.

In the current study, we evaluated the expression of ERCC6L in HCC patients and demonstrated that ERCC6L levels were overexpressed in the tumor tissues than in paired tumor-adjacent tissues. Meanwhile, ERCC6L expression levels were positively associated with clinicopathological characteristics, including Edmondson stage, tumor encapsulation, and female gender. Furthermore, abnormal expression of ERCC6L was associated with shorter OS compared with low ERCC6L expression in patients, indicating that ERCC6L expression is markedly significant for the prognosis of HCC patients. Epidemiological studies of HCC have showed that it was notably more prevalent in male than in female, with a male-to- female ratio ranging from 2:1 to 8: 1 [27]. We also found that ERCC6L expression was higher in man than that of women. Although in line with this trend, however the proportion of female patients in our sample was lower, than it may need to further expand the sample size for further research. High ERCC6L expression was also found in the patients with non-tumor encapsulation or III-IV pathological stage, which often indicating highly invasive, metastatic, and poor prognosis.

Similarly, the level of ERCC6L mRNA and proteins expression was also elevated in HCC cell lines than in normal human liver cells. Then, we revealed that interfering with ERCC6L expression with shRNA in SMMC-7721 and $\mathrm{HuH}-7$ cells significantly inhibited their proliferation in vitro and in vivo. Apoptosis is a cellular mechanism characterized with programmed cell death and is result of chain of reaction modulated by many effectors for regulating coordinates cell proliferation and cell death [28]. Previous studies have observed that caspase 3 is considered as a crucial executioner of apoptosis and activated caspase $3 / 7$ may cleave the majority of polypeptides which undergo proteolysis in cells, and was an independent prognostic factor for tumor [29] . Knockdown ERCC6L promoted the G1 phase cell arrest and increased the proportion of apoptosis cells by caspase $3 / 7$ dependent manner. Collectively, these data indicated that ERCC6L may function as an oncogene in the occurrence and development of the HCC.

Numerous studies have shown that the PI3K/AKT signaling pathway plays a crucial role in malignant transformation and the subsequent growth, proliferation, and metastasis of human tumors $[30,31]$. The downstream effectors of abnormal activated PI3K/AKT pathway may contribute to its role in progression of tumor growth, apoptosis, altered endothelial cell function, and angiogenesis, such as NF- $\mathrm{kB}$ and mTOR [32-35]. In a clinical study, PI3K/AKT pathway activation was associated with tumor progression and the reduced survival of HCC patients [36]. Caspases-7 and caspases-3 are involved in the initiation and execution of apoptosis, respectively. Activated AKT can phosphorylate caspases-7 and caspases-3 to prevent caspase- 9 and caspase- 3 activation [37]. We investigated the mechanism by which ERCC6L shRNA inhibited HCC progress. Results revealed that knockdown-ERCC6L expression reduced the level of phosphodiesters related to the PI3K/AKT and NF- $\mathrm{kB}$. Furthermore, the rescue experiments clarified that AKT inhibitor attenuated the enhancement of upregulating mediated $\mathrm{p}-\mathrm{PI} 3 \mathrm{~K} / \mathrm{p}-\mathrm{AKT}$ and $\mathrm{p}-\mathrm{NF}-\mathrm{kB}$ protein expression. These data suggested that ERCC6L may regulate HCC via PI3K/AKT pathway (Fig. 5d). This may provide a new direction for studying ERCC6L function.

\section{Conclusions}

This study demonstrated that the ERCC6L expression was upregulated in HCC tumor tissue, which exhibited closely associated with tumor progression and poor prognosis. Furthermore, aberrant expression of ERCC6L promoted tumorigenesis via the PI3K/AKT and NF- $\mathrm{kB}$ pathway. Hence, ERCC6L may be a potential therapeutic target for HCC.

\section{Supplementary information}

Supplementary information accompanies this paper at https://doi.org/10. 1186/s12885-020-07367-2.

Additional file 1: Figure S1. Uncropped full-length blot images for Fig. $2 b, 4 a, b$. The cropped blots were marked with red frame.

\section{Abbreviations}

ERCC6L: Excision Repair Cross-Complementation group 6-like; HCC: Hepatocellular Carcinoma; PI3K: Phosphoinositide 3-kinase; AKT: Protein kinase B; NF-kB: Nuclear factor-kappa B; OS: Overall survival rates

\section{Acknowledgements}

Not applicable.

\section{Authors' contributions}

$\mathrm{CH}, \mathrm{SHH}$ and ZXW participated in the conception and design of the study. $\mathrm{CH}, \mathrm{HXW}, \mathrm{XQY}$, and SPZ performed the experiments, and prepared the manuscript. YYZ and ZPW performed the data analysis. $\mathrm{CH}$ drafted the paper. $\mathrm{SHH}$ and ZXW participated in the final preparation and revision of the paper. All authors read and approved the final manuscript.

\section{Funding}

This work was supported by the Project Program of the National Natural Science Foundation of China [81303077,81971088]; The Project of Medicine Science and Technology Development of Shandong [2017WS268]; Natural Science Foundation of Shandong Province [ZR2018LH012, ZR2019BH033]. The funders had no role in the study design, data analysis and interpretation of these data; writing the manuscript and the decision to publish the results. 


\section{Availability of data and materials}

All datasets generated for this study are included in the manuscript and/or the supplementary files.

\section{Ethics approval and consent to participate}

This research was approved by Ethics Committee of the Institute of Basic Medicine, Shandong Academy of Medical Sciences.

\section{Consent for publication}

Not applicable.

\section{Competing interests}

The authors declare that the research was conducted in the absence of any commercial or financial relationships that could be construed as a potential conflict of interest.

\section{Received: 6 November 2019 Accepted: 31 August 2020}

\section{Published online: 05 September 2020}

\section{References}

1. El-Serag HB, Rudolph KL. Hepatocellular carcinoma: epidemiology and molecular carcinogenesis. Gastroenterology. 2007;132(7):2557-76.

2. Cui C, Fu K, Yang L, Wu S, Cen Z, Meng X, Huang Q, Xie Z. Hypoxiainducible gene 2 promotes the immune escape of hepatocellular carcinoma from nature killer cells through the interleukin-10-STAT3 signaling pathway. J Exp Clin Cancer Res. 2019:38(1):229.

3. Forner A, Llovet JM, Bruix J. Hepatocellular carcinoma. Lancet. 2012; 379(9822):1245-55.

4. Kuzuya T, Ishigami M, Ishizu Y, Honda T, Hayashi K, Ishikawa T, Nakano I, Hirooka Y, Goto H. Prognostic factors associated with Postprogression survival in advanced hepatocellular carcinoma patients treated with Sorafenib not eligible for second-line Regorafenib treatment. Oncology. 2018:95(2):91-9.

5. Bosetti C, Turati F, La Vecchia C. Hepatocellular carcinoma epidemiology. Best Pract Res Clin Gastroenterol. 2014:28(5):753-70.

6. Albers E, Sbroggio M, Pladevall-Morera D, Bizard AH, Avram A, Gonzalez P, Martin-Gonzalez J, Hickson ID, Lopez-Contreras AJ. Loss of PICH results in chromosomal instability, p53 activation, and embryonic lethality. Cell Rep. 2018;24(12):3274-84.

7. Xu Y, Chen X, Li Y. Ercc6l, a gene of SNF2 family, may play a role in the teratogenic action of alcohol. Toxicol Lett. 2005;157(3):233-9.

8. Hubner NC, Wang LH, Kaulich M, Descombes P, Poser I, Nigg EA. Reexamination of siRNA specificity questions role of $\mathrm{PICH}$ and Taol in the spindle checkpoint and identifies Mad2 as a sensitive target for small RNAs. Chromosoma. 2010;119(2):149-65.

9. Liu J, Sun J, Zhang Q. Zeng Z: shRNA knockdown of DNA helicase ERCC6L expression inhibits human breast cancer growth. Mol Med Rep. 2018;18(3): 3490-6

10. Pu SY, Yu Q, Wu H, Jiang JJ, Chen XQ, He YH, Kong QP. ERCC6L, a DNA helicase, is involved in cell proliferation and associated with survival and progress in breast and kidney cancers. Oncotarget. 2017;8(26):42116-24.

11. Zhong X, Liu Y, Liu H, Zhang Y, Wang L, Zhang H. Identification of potential prognostic genes for neuroblastoma. Front Genet. 2018;9:589.

12. Chen $Y$, Zhu W. Knockdown of the sonic hedgehog $(\mathrm{SHH})$ gene inhibits proliferation of Hep3B and SMMC-7721 hepatocellular carcinoma cells via the PI3K/Akt/PCK1 signaling pathway. Med Sci Monit. 2019;25:6023-33.

13. Yan SY, Chen MM, Li GM, Wang YQ, Fan JG. MiR-32 induces cell proliferation, migration, and invasion in hepatocellular carcinoma by targeting PTEN. Tumour Biol. 2015;36(6):4747-55.

14. Dong QZ, Wang Y, Dong XJ, Li ZX, Tang ZP, Cui QZ, Wang EH. CIP2A is overexpressed in non-small cell lung cancer and correlates with poor prognosis. Ann Surg Oncol. 2011;18(3):857-65.

15. Choi H, Roh J. Role of Klf4 in the Regulation of Apoptosis and Cell Cycle in Rat Granulosa Cells during the Periovulatory Period. Int J Mol Sci. 2018;20(1):87.

16. Chen H, Zhidan W, Xia R, Zhaoxia W, Qing J, Qiang G, Haipeng Y, Hengxiao W. Scorpion venom activates natural killer cells in hepatocellular carcinoma via the NKG2D-MICA pathway. Int Immunopharmacol. 2016;35:307-14.

17. Udager AM, Ishikawa MK, Lucas DR, McHugh JB, Patel RM. MYC immunohistochemistry in angiosarcoma and atypical vascular lesions: practical considerations based on a single institutional experience. Pathology. 2016;48(7):697-704.
18. Hu Z, Gu X, Zhong R, Zhong H. Tumor-infiltrating CD45RO(+) memory cells correlate with favorable prognosis in patients with lung adenocarcinoma. J Thorac Dis. 2018;10(4):2089-99.

19. Zhang Y, Kwok-Shing Ng P, Kucherlapati M, Chen F, Liu Y, Tsang YH, de Velasco G, Jeong KJ, Akbani R, Hadjipanayis A, et al. A pan-Cancer Proteogenomic atlas of PI3K/AKT/mTOR pathway alterations. Cancer Cell. 2017;31(6):820-32 e823.

20. Fu HW, Lin X, Zhu YX, Lan X, Kuang Y, Wang YZ, Ke ZG, Yuan T, Chen P. Circ-IGF1R has pro-proliferative and anti-apoptotic effects in HCC by activating the PI3K/AKT pathway. Gene. 2019;716:144031.

21. Jiang S, Wang Q, Feng M, Li J, Guan Z, An D, Dong M, Peng Y, Kuerban K, Ye L. C2-ceramide enhances sorafenib-induced caspase-dependent apoptosis via PI3K/AKT/mTOR and Erk signaling pathways in HCC cells. Appl Microbiol Biotechnol. 2017;101(4):1535-46.

22. Pikarsky E, Porat RM, Stein I, Abramovitch R, Amit S, Kasem S, GutkovichPyest E, Urieli-Shoval S, Galun E, Ben-Neriah Y. NF-kappaB functions as a tumour promoter in inflammation-associated cancer. Nature. 2004; 431(7007):461-6.

23. Dutta R, Mahato RI. Recent advances in hepatocellular carcinoma therapy. Pharmacol Ther. 2017:173:106-17.

24. Feng R, Ye J, Zhou C, Qi L, Fu Z, Yan B, Liang Z, Li R, Zhai W. Calreticulin downregulation inhibits the cell growth, invasion and cell cycle progression of human hepatocellular carcinoma cells. Diagn Pathol. 2015;10:149.

25. Zhang G,Yu Z,Fu S, Lv C, Dong Q, Fu C, Kong C, Zeng Y. ERCC6L that is upregulated in high grade of renal cell carcinoma enhances cell viability in vitro and promotes tumor growth in vivo potentially through modulating MAPK signalling pathway. Cancer Gene Therapy. 2019;26(9-10): 323-33.

26. Xie Y, Yu J, Wang F, Li M, Qiu X, Liu Y, Qi J. ERCC6L promotes cell growth and invasion in human colorectal cancer. Oncol Lett. 2019;18(1):237-46.

27. Han Q, Yang D, Yin C, Zhang J. Androgen receptor (AR)-TLR4 crosstalk mediates gender disparities in hepatocellular carcinoma incidence and progression. J Cancer. 2020;11(5):1094-103.

28. Wang XQ, Bai HM, Li ST, Sun H, Min LZ, Tao BB, Zhong J, Li B. Knockdown of HDAC1 expression suppresses invasion and induces apoptosis in glioma cells. Oncotarget. 2017;8(29):48027-40.

29. Chen $H$, Yang $X$, Feng Z, Tang R, Ren F, Wei K, Chen G. Prognostic value of Caspase-3 expression in cancers of digestive tract: a meta-analysis and systematic review. Int J Clin Exp Med. 2015;8(7):10225-34.

30. Liu P, Cheng H, Roberts TM, Zhao JJ. Targeting the phosphoinositide 3kinase pathway in cancer. Nat Rev Drug Discov. 2009;8(8):627-44.

31. Wang $Y$, Yuan $L$, Yang XM, Wei D, Wang B, Sun XX, Feng F, Nan G, Wang $Y$, Chen ZN, et al. A chimeric antibody targeting CD147 inhibits hepatocellular carcinoma cell motility via FAK-PI3K-Akt-Girdin signaling pathway. Clin Exp Metastasis. 2015;32(1):39-53.

32. Zhang Z, Zhu J, Huang Y, Li W, Cheng H. MYO18B promotes hepatocellular carcinoma progression by activating PI3K/KT/mTOR signaling pathway. Diagn Pathol. 2018;13(1):85.

33. Yang J, Pi C, Wang G. Inhibition of PI3K/Akt/mTOR pathway by apigenin induces apoptosis and autophagy in hepatocellular carcinoma cells. Biomed Pharmacother. 2018;103:699-707.

34. Bidkhori G, Benfeitas R, Klevstig M, Zhang C, Nielsen J, Uhlen M, Boren J, Mardinoglu A. Metabolic network-based stratification of hepatocellular carcinoma reveals three distinct tumor subtypes. Proc Natl Acad Sci U S A. 2018;115(50):E11874-83.

35. Manning BD, Toker A. AKT/PKB signaling: navigating the network. Cell. 2017; 169(3):381-405

36. Yan H, Jung KH, Kim J, Rumman M, Oh MS, Hong SS. Artemisia capillaris extract AC68 induces apoptosis of hepatocellular carcinoma by blocking the PI3KJAKT pathway. Biomed Pharmacother. 2018;98:134-41.

37. Nguyen ST, Huynh KL, Nguyen HL, Nguyen Thi Thanh M, Nguyen Trung N, Nguyen Xuan H, Ngoc KP, Truong Dinh K, Pham PV. Hopea odorata extract inhibits hepatocellular carcinoma via induction of caspase-dependent apoptosis. OncoTargets Therapy. 2017;10:5765-74.

\section{Publisher's Note}

Springer Nature remains neutral with regard to jurisdictional claims in published maps and institutional affiliations. 